\title{
The Utilization of a Fish Pump for Harvesting Shrimp from Tanks and Ponds 1
}

\author{
Cortney L. Ohs, Scott W. Grabe, R. LeRoy Creswell ${ }^{2}$
}

\section{Introduction}

Commercial shrimp farms located throughout the world utilize several techniques to harvest shrimp from ponds and raceways. Commonly, farmers drain their systems and collect shrimp in nets, mesh bags or baskets as water passes through the drain. Other methods for partial harvest include cast netting or trapping the shrimp as water exits the pond gates during receding tides. Recently, modified mechanical pumps have proven to be very effective at harvesting shrimp from ponds and raceways.

Some commercial farms now use mechanical pumps to reduce the time and labor required to harvest. Farms that sell to certain high-end markets are often unable to use collection methods involving nets, mesh bags or baskets because the shrimp can be damaged during harvest.

At the University of Florida shrimp demonstration facility (IFAS/IRREC), protocols have been established for effective use of a fish pump to harvest juvenile and adult Pacific white shrimp, Litopenaeus vannamei, from ponds and raceways. These protocols can reduce time and labor costs, improve product quality, and can be used with other aquatic organisms.

\section{Description of the Fish Pump}

The fish pump we tested was a gasoline powered Heathro fish pump which consisted of a Honda GX270 motor, a 2.5 gallon (9.5 L) gasoline tank, an industrial priming pump and two 6-inch $(15.2 \mathrm{~cm})$ camlock fittings for attaching hoses to the top and side of the round fiberglass housing (Figure 1). The fiberglass housing of the pump contains a single-vane cast aluminum impeller designed to prevent damage to the shrimp during transfer. This unit is mounted on a cart equipped with two handle bars and pneumatic wheels for manual mobility (Figure 1). The cart design allows farmers to use other accessories such as a dewatering tower and/or holding tanks to help improve the harvest process.

Several companies manufacture and market fish pumps and there are various models and sizes available. The University of Florida shrimp demonstration facility only evaluated the Heathro fish pump. A list of some currently available fish pumps and accessories is provided in the appendix.

1. This document is FA123, from the Department of Fisheries and Aquatic Sciences, Florida Cooperative Extension Service, Institute of Food and Agricultural Sciences, University of Florida. First published: February 2006. Please visit the EDIS Web Site at http://edis.ifas.ufl.edu.

2. Cortney L. Ohs, Assistant Professor; Scott W. Grabe, Research Technician, Indian River Research and Extension Center and the Department of Fisheries and Aquatic Sciences, Fort Pierce, Fl. R. LeRoy Creswell, Marine Extension Agent, St. Lucie County Cooperative Extension, Fort Pierce, Fl.

The Institute of Food and Agricultural Sciences (IFAS) is an Equal Opportunity Institution authorized to provide research, educational information and other services only to individuals and institutions that function with non-discrimination with respect to race, creed, color, religion, age, disability, sex, sexual orientation, marital status, national origin, political opinions or affiliations. U.S. Department of Agriculture, Cooperative Extension Service, University of Florida, IFAS, Florida A. \& M. University Cooperative Extension Program, and Boards of County Commissioners Cooperating. Larry Arrington, Dean 


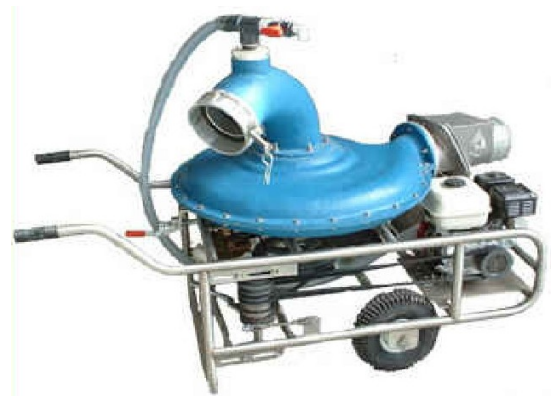

Figure 1. Cart-mounted fish pump unit. Credits: http://praquasupplies.com/heathro.htm

\section{Harvest Preparation and Layout}

Prior to harvest day, the pond should be partially drained to expedite the time it takes to complete the harvest. A gate valve or standpipe can be used to regulate the amount of water leaving the pond during this draining process. The gate valve or standpipe should be covered with mesh screening to prevent the shrimp from being flushed out of the pond during draining. In addition, oil and gasoline levels should be checked in the pump and filled to appropriate levels. Belts should be inspected for proper tension and attrition and pressure in the pneumatic tires should be checked and adjusted appropriately.

After inspection, the cart should be positioned next to the drain of the pond or raceway on the outer bank of the retention pond or drainage canal where the water is released (Figure 2). On soft ground, the cart should be placed on top of a 4 foot $(1.2 \mathrm{~m})$ by 8 foot $(2.4 \mathrm{~m})$ sheet of plywood or supported by concrete blocks for stability. Next, a 12-inch by 6-inch $(30.4 \mathrm{~cm}$ by $15.2 \mathrm{~cm}$ ) adapter should be mounted onto the pond drain with screws to allow for the attachment of the male adapter 6-inch $(15.2 \mathrm{~cm})$ intake pump hose. The adapter should be equipped with holes to help accelerate the draining process of the pond by diverting part of the water directly into the retention pond or drainage canal. After attachment, the male adapter of the 6-inch flexible hose is connected into the female camlock fitting located on top of the fiberglass housing. Small screws should also be inserted between the 6-inch $(15.2 \mathrm{~cm})$ intake hose and adapter to prevent detachment during harvest.

After the intake hoses are connected, the remaining pipes and accessories are positioned and

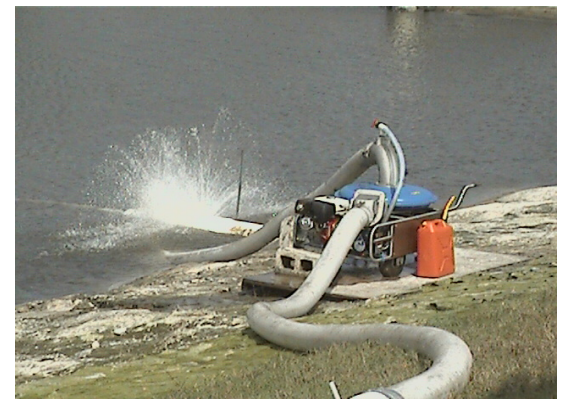

Figure 2. Fish pump operating from the outer-bank of the retention pond. Credits: Scott W. Grabe

assembled along the discharge section of the layout. A dewatering tower and two holding tanks are included to facilitate the collection of shrimp and allow for easy packaging. The dewatering tower and holding tanks need to be placed next to each other and near an adjacent pond or on the levee of the retention pond or canal where the water is being discharged (Figure 3). This arrangement allows the shrimp to be directly discharged into the holding tanks from the dewatering tower. In addition, the water leaving the tower and holding tanks can be diverted into an adjacent pond or canal and reused. Set-up is completed once the hose connections are made between the pump and dewatering tower.

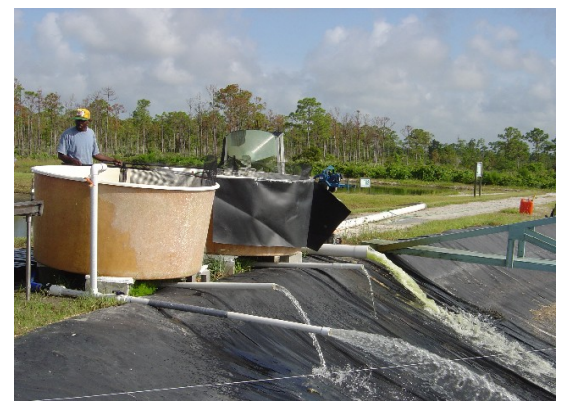

Figure 3. The arrangement of the green dewatering tower and the two round holding tanks on the levee. Credits: Cortney L. Ohs

\section{Harvest Procedure Using the Gas Model Heathro Fish Pump}

After pond preparation is completed and all equipment has been checked and positioned properly, follow the procedures outlined below to harvest the shrimp:

1. Push the impellor lever inward to the "OFF" position. 
2. Set the prime pump to the "OFF" position by sliding the lever all the way to the left.

3. Fill the fish pump water reservoir tank with a hose or bucket until it overflows.

4. Close the pump body and water reservoir drains.

5. Close the vacuum valve located on top of the inlet elbow.

6. Turn the red power Honda motor switch to the "ON" position.

7. Pull the black starter cord until the pump starts (Apply choke if necessary).

8. With the motor running, increase the throttle to full speed to minimize shaking and improve suction.

9. Set the prime pump to the "ON" position by sliding the lever all the way to the right.

10. Once the pump is primed, disengage the prime pump by sliding the lever all the way to the left.

11. Pull the impellor lever outward to the "ON" position.

12. Adjust the throttle to the desired flow rate of water into the dewatering tower.

13. Remove the standpipe from harvest pond to allow for the transfer of shrimp through the fish pump.

14. Use hand nets to remove the shrimp out of the holding tank. (Figure 4).

15. Rinse the shrimp in the adjacent holding tank with clean water to reduce the chances of off-flavor.

16. Weigh and package the shrimp for marketing.

17. Open the water supply line of the pond or tanks to flush the remaining shrimp through the drain.

In the last step of the procedure, the water supply line to the pond or tank should be opened to flush the remaining shrimp down the drain because

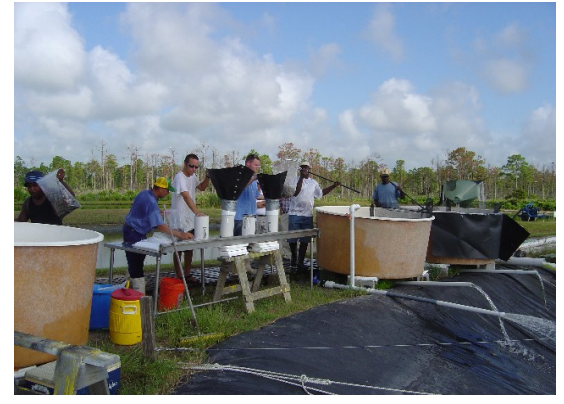

Figure 4. Netting, rinsing, weighing, and packaging process. Credits: Cortney L. Ohs

many shrimp tend to remain with the last of the water. The additional supply of water also helps to prevent pump cavitations during the end of the transfer process. If necessary, seine nets can be used to crowd the shrimp towards the pond drain during harvest. This can reduce the number of shrimp that remain in the pond until the very end of draining.

\section{Additional Applications for Fish Pumps}

Fish pumps can also be used to transfer juvenile shrimp between tanks or from tanks to ponds. This type of transfer requires the fish pump to be attached to the tank drain line or a pipe that is submersed into a drainage sump. We have successfully transferred 400,000 juvenile shrimp over a horizontal distance of 200 feet $(61 \mathrm{~m})$ in less than two hours without any observed mortality or damage to the shrimp.

The system can be modified to include a computerized counter to quantify the shrimp during the transfer process between tanks and/or ponds. In this application, the counter should be integrated downstream from the de-watering tower in the discharge section of the layout. The downward sloping design of the tower allows for the direct discharge of shrimp into the counter (Figure 5). In addition, a 4-inch $(10.16 \mathrm{~cm}) \mathrm{PVC}$ pipe with valves can be positioned at the effluent end of the counter to direct a known number of shrimp into selected ponds or tanks. This approach eliminates the need to dismantle and move the system when stocking multiple ponds or tanks. 


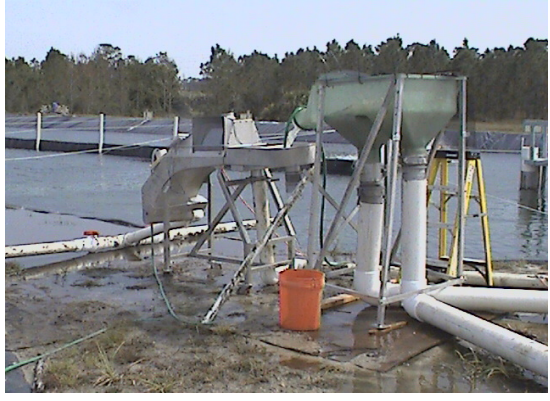

Figure 5. Incorporation of the shrimp counter (left) with the dewatering tower. Credits: Scott W. Grabe

\section{Potential Pitfalls when Using the Fish Pump}

Several potential pitfalls have been identified when using a fish pump. Firstly, it is very important to inspect the belts before operating the pump. Belts that are loose or in poor condition could dislodge when the pump vibrates. Secondly, the fish pump operates at a maximum speed of 634 gallons/minute $(2,400 \mathrm{~L} / \mathrm{min})$, so it is necessary to drain partially the large production ponds in order to complete the harvest within one day. Finally, when the water levels in the pond get low, the fish pump can experience cavitations and loose its prime. Therefore, it is recommended when the final water and shrimp remain in the pond bottom, that sufficient additional water is provided to prevent cavitations and to dilute the concentrated sediments that may occur in the pond bottom. This allows the final shrimp to be efficiently harvested and prevents the shrimp from having prolonged exposure to concentrated sediments that can cause off-flavor. In addition, thoroughly rinsing and washing the final shrimp harvested in the holding tanks is highly recommended.

\section{Summary}

A mechanical fish pump can be an effective tool for harvesting and transferring shrimp between tanks and/or ponds. The use of a pump can reduce time and labor costs associated with harvesting shrimp while improving product quality.

The cart design provides maneuverability and it can be operated on all types of terrain. The motor design permits the harvest and transfer of shrimp over relatively long horizontal distances. This provides the capability to transfer shrimp between tanks, ponds, and packaging facilities at various locations within the farm site.

Additionally, a computerized counter can be integrated with the fish pump to quantify the shrimp that are transferred or harvested. This allows farmers to stock ponds or tanks with a specified number of shrimp or to quantify shrimp as they are harvested. Finally, other accessories, such as de-watering towers or conveyor belts, can be utilized to further automate harvesting.

\section{Appendix}

The University of Florida does not endorse any particular brand of equipment mentioned but wants to familiarize producers about different types of equipment which are currently available and have functioned well in our demonstration projects.

$\underline{\text { Vendors }}$

1. PRAqua Technologies Ltd. http://praquasupplies.com/heathro.htm

2. Magic Valley heli-Arc and Manufacturing Inc. http://www.aqualifeproducts.com/ shrimpharvester.htm

3. MIPR Corporation http://www.miprcorp.com/fishpump.html

\section{$\underline{\text { Shrimp Counters }}$}

1. PRAqua Technologies Ltd.

http://praquasupplies.com/mic_mac.htm 